\title{
Frequent associations between CTL and T-Helper epitopes in HIV-1 genomes and implications for multi-epitope vaccine designs
}

\author{
Sinu Paul, Helen Piontkivska*
}

\begin{abstract}
Background: Epitope vaccines have been suggested as a strategy to counteract viral escape and development of drug resistance. Multiple studies have shown that Cytotoxic T-Lymphocyte (CTL) and T-Helper (Th) epitopes can generate strong immune responses in Human Immunodeficiency Virus (HIV-1). However, not much is known about the relationship among different types of HIV epitopes, particularly those epitopes that can be considered potential candidates for inclusion in the multi-epitope vaccines.

Results: In this study we used association rule mining to examine relationship between different types of epitopes (CTL, Th and antibody epitopes) from nine protein-coding HIV-1 genes to identify strong associations as potent multi-epitope vaccine candidates. Our results revealed 137 association rules that were consistently present in the majority of reference and non-reference HIV-1 genomes and included epitopes of two different types (CTL and Th) from three different genes (Gag, Pol and Nef). These rules involved 14 non-overlapping epitope regions that frequently co-occurred despite high mutation and recombination rates, including in genomes of circulating recombinant forms. These epitope regions were also highly conserved at both the amino acid and nucleotide levels indicating strong purifying selection driven by functional and/or structural constraints and hence, the diminished likelihood of successful escape mutations.

Conclusions: Our results provide a comprehensive systematic survey of $C T L$, Th and Ab epitopes that are both highly conserved and co-occur together among all subtypes of HIV-1, including circulating recombinant forms. Several co-occurring epitope combinations were identified as potent candidates for inclusion in multi-epitope vaccines, including epitopes that are immuno-responsive to different arms of the host immune machinery and can enable stronger and more efficient immune responses, similar to responses achieved with adjuvant therapies. Signature of strong purifying selection acting at the nucleotide level of the associated epitopes indicates that these regions are functionally critical, although the exact reasons behind such sequence conservation remain to be elucidated.
\end{abstract}

\section{Background}

Human Immunodeficiency Virus (HIV), the virus responsible for Acquired Immunodeficiency Syndrome (AIDS), is one of the major causes of death around the world today. There were 2.1 million AIDS related deaths and 2.5 million new infections in 2007 alone with over 33.2 million people living with HIV-1 infection (AIDS epidemic update 2007, UNAIDS). Although the use of the Highly Active Anti-Retroviral Therapy (HAART)

\footnotetext{
*Correspondence: opiontki@kent.edu

Department of Biological Sciences, Kent State University, Kent, Ohio, 44242,
} USA

() 2010 Paul and Piontkivska; licensee BioMed Central Ltd. This is an Open Access article distributed under the terms of the Creative

has significantly reduced the mortality and morbidity of HIV patients by chronically suppressing HIV-1 replication, we are far from finding a cure [1,2]. Moreover, drug regimens not only come with many drawbacks such as increased malignancies, insulin resistance, glucose intolerance and diabetes mellitus [3,4]. Other challenges to HAART efficiency are development of latency and drug resistance as viruses mutate and escape from the drug action [5-8]. Despite isolated stories about cures for HIV infection [9] and a recent modest success in a clinical vaccine trial $[10,11]$, a vaccine that can give 
total protection and a drug that can give complete cure remain to be designed $[12,13]$.

Immune response to the HIV infection consists of a combination of both humoral and cellular immunity $[14,15]$. Furthermore, different immune responses can target the same regions of viral peptides. For example, V3-loop peptides of the Env gene can be presented by both class I and class II major histocompatibility complex (MHC) molecules and can be recognized by both Cytotoxic T-Lymphocytes (CTLs) and T-Helper cells (Th), as well as by neutralizing antibodies (Ab) (e.g., [16-18]). Likewise, a highly conserved region in the Gag gene (287-309 amino acid residues in p24) has been shown to interact with CTL, as well as B and T-Helper cells [19]. This, in turn, implies that escape changes driven by the selection pressure from one type of the host immune response can also lead to escape from a different immune mechanism (e.g., [20]). Recently, epitope vaccines (vaccines that contain synthetic peptides representing epitopes from pathogens) against HIV as well as other viruses such as Influenza have been suggested as a new strategy to avoid the viral escape from the host immune system as well as to counteract development of resistance against drugs [21-24]. While recognition of epitopes by the host immune system and mounting of immune response against pathogen is important in controlling and prevention of infections [25], mutations in the epitope regions can help pathogens to evade recognition by immune receptors and lead to subsequent escape of host immune system [26-28]. Selection by the immune system that promotes amino acid sequence diversification at viral epitopes has been shown to play a significant role in the evolution of different viruses, including HIV-1, SIV, Hepatitis C virus, and the Influenza A virus (e.g., [29-32]).

Based on the type of recognizing receptors, there are three types of epitopes, namely $\mathrm{CTL} / \mathrm{CD} 8^{+}$epitopes (CTL), T-Helper/CD4 ${ }^{+}$epitopes (Th) and neutralizing antibody $(\mathrm{Ab})$ epitopes. Single and multi-epitope vaccines containing CTL, Th and Ab epitopes have been described [33,34]. Inclusion of highly conserved epitopes from different genomic regions in a multi-epitope vaccine has been suggested as a strategy to induce a broader cellular immune response that targets the majority of the virus variants $[33,35,36]$. However, identification of good vaccine candidates based on the extent of sequence conservation in HIV is a challenging problem, compounded by the fast mutation $[37,38]$ and recombination rates [39-41], overlapping reading frames [42] and overall high degree of sequence divergence among the global HIV-1 population [43].

Recently, we reported a series of highly conserved, co-occurring CTL epitopes from three different genes (Gag, Pol and Nef) that are frequently found in association with each other and therefore can be considered strong candidates for inclusion in CTL multiepitope vaccines [44]. However, to further improve the vaccine efficiency, the use of adjuvants capable of inducing a strong cellular response and potentially augmenting these responses should be considered (e.g., [45-48]), including use of multiple types of epitopes [49]. For example, Gram et al. (2009) [49] recently showed that while the use of immune-stimulating adjuvant CAF01 induces strong a CTL response, inclusion of a CD4 T-Helper epitope further improves this CTL response.

Thus, this study was focused on identifying strong associations between different types of epitopes from multiple genes in search of potent multi-epitope vaccine candidates. Our results identified several highly conserved T-Helper epitopes that frequently co-occur with particular highly conserved CTL epitopes and that these epitopes co-occur in the majority of HIV-1 genomes of different subtypes and groups as well as circulating recombinant forms. Here we report 137 unique CTL and T-Helper epitope associations (also referred to as association rules) that involve epitopes from 14 nonoverlapping genomic regions from three different genes, namely, Gag, Pol and Nef. Widespread presence of these epitope combinations across highly divergent HIV-1 genomes sampled worldwide, including circulating recombinant forms, coupled with a high degree of evolutionary sequence conservation likely reflective of substantial fitness impacts of escape mutations [50] makes them potent candidates for a multi-epitope vaccine.

\section{Methods}

HIV-1 genomic sequence data and sequence alignment

HIV-1 sequences in the primary analysis included 90 HIV-1 reference sequences from the 2007 subtype reference set of the HIV Sequence database (Los Alamos National Laboratory (LANL), http://www.hiv.lanl.gov), which included full length genomes containing sequences from all nine protein-coding genes, one sequence per patient (List of sequences, including GenBank accession numbers, is described in the Additional file 1). Amino acid and nucleotide sequence alignments were collected separately for analyses of epitope presence and estimation of nucleotide substitution rates, respectively. These curated alignments were generated using HMMER and verified manually (HIV sequence database by LANL). Further details about sequence alignments and selection of reference sequences are available in the HIV Sequence Database and Leitner et al. (2005) [51], respectively. This reference set was comprised of 47 non-recombinant sequences, including 40 sequences from $M$ group (representing subtypes A1, A2, B, C, D, F1, F2, G, H, J, and K), 7 sequences from $\mathrm{N}$ and $\mathrm{O}$ groups and 43 recombinant sequences, with approximately 4 representatives for each 
subtype (Table 1). We used this reference sequence set because it roughly approximates the diversity of each subtype as represented in the database. Inclusion of circulating recombinant forms (CRFs) that are defined as inter-subtype recombinant viruses identified from more than a single patient and spreading epidemically $[52,53]$, allowed us to capture those highly conserved epitopes that are shared with non-recombinant genomes and are also present in the majority of the recombinant reference genomes.

\section{HIV-1 Epitopes}

The sets of CTL, T-Helper and antibody epitopes were collected from the HIV Immunology database (Los Alamos National Laboratory, http://www.hiv.lanl.gov/content/ immunology) [54], the most comprehensive curated source of known HIV epitopes [55]. A total of 606 linear epitopes were collected, including 229 CTL epitopes that were described as the "best defined" CTL epitopes and were supported by strong experimental evidence, as defined by Frahm et al., 2007 [56], 296 T-Helper epitopes and 81 antibody epitopes (Table 2, Additional file 2). Because of the challenges in identifying primary sequence elements of structurally conserved discontiguous conformational epitopes (e.g., [57,58]), conformational epitopes were not included in the study. Only the epitopes proven to be immunogenic in human as per the HIV Immunology database were used in this study. The overview of epitope mapping techniques and challenges in epitope identification has been described elsewhere [59,60]. Although CTL and Th epitopes had representation from all nine proteincoding genes, Ab epitopes were absent in the Vif, Vpr, Rev and $V p u$ genes. The majority of the Ab epitopes (75 out of 81) belonged to the Env gene, while the Pol gene had three and the Gag, Tat and Nef genes had one epitope each [61-65]. It should be noted that because of the high amino acid sequence diversity of the Env gene that may differ by as much as $30 \%$ between subtypes [43], very few antibody epitopes if at all could be expected to be conserved across a broad range of HIV-1 sequences; thus, in this study we primarily focus on CTL and T-Helper epitopes. Restricting HLA allele(s) for associated epitopes are given in Table 3 as per HIV Immunology database and IEDB http://www.immuneepitope.org/.

\section{Inclusion of epitopes in association-rule mining}

In order to identify the most broadly represented epitopes, each epitope sequence was aligned with 90 reference sequences and the epitopes present in more than $75 \%$ of the reference sequences (i.e., perfect amino acid sequence match in more than 67 sequences) were selected for association rule mining. A total of 47 epitopes, including $33 \mathrm{CTL}, 12 \mathrm{~T}$-Helper and 2 antibody epitopes, were present in more than $75 \%$ of the reference

Table 1 Overview of HIV-1 sequences used in the analyses

\begin{tabular}{|c|c|c|c|c|c|}
\hline Type of genome & Group & Subtype & Reference sequences $^{\#}$ & Non-reference sequences* & Total (Global HIV-1 population ${ }^{\wedge}$ ) \\
\hline \multirow[t]{17}{*}{ Non - recombinant } & M group & A & - & 6 & 6 \\
\hline & & A1 & 4 & 46 & 50 \\
\hline & & $\mathrm{A} 2$ & 3 & - & 3 \\
\hline & & B & 5 & 158 & 163 \\
\hline & & C & 4 & 350 & 354 \\
\hline & & $\mathrm{D}$ & 4 & 32 & 36 \\
\hline & & F1 & 4 & 6 & 10 \\
\hline & & F2 & 4 & - & 4 \\
\hline & & G & 4 & 12 & 16 \\
\hline & & $\mathrm{H}$ & 3 & - & 3 \\
\hline & & J & 3 & - & 3 \\
\hline & & K & 2 & - & 2 \\
\hline & & M - Total & 40 & 610 & 650 \\
\hline & $\mathrm{N}$ group & & 3 & 2 & 5 \\
\hline & O group & & 4 & 13 & 17 \\
\hline & & N \& O Total & 7 & 15 & 22 \\
\hline & Non-recon & inants - Total & 47 & 625 & 672 \\
\hline \multicolumn{3}{|c|}{ Circulating Recombinant Forms (CRF) } & 43 & 263 & 306 \\
\hline & & Total & 90 & 888 & 978 \\
\hline
\end{tabular}

The table shows numbers of HIV-1 sequences of different subtypes among reference sequences and global population used in the analyses.

\# Reference sequences used in the primary analyses to identify association rules

* Non-reference sequences were collected from 2008 Web alignment of HIV Sequence database

${ }^{\wedge}$ Total number of sequences in the global HIV-1 population used in the analysis 
Table 2 Overview of epitopes used in the analyses

\begin{tabular}{|c|c|c|c|c|c|c|c|c|c|c|c|c|c|}
\hline \multirow[t]{2}{*}{ Gene } & \multirow[t]{2}{*}{ Protein } & \multicolumn{4}{|c|}{ Total no. of epitopes } & \multicolumn{4}{|c|}{ Highly conserved epitopes* } & \multicolumn{4}{|c|}{ No of associated epitopes ${ }^{\wedge}$} \\
\hline & & $\mathrm{CTL}^{\#}$ & Th & $A b$ & Total & CTL & Th & $A b$ & Total & CTL & Th & $A b$ & Total \\
\hline \multirow[t]{4}{*}{ Gag } & p17 & 18 & 32 & - & 50 & 1 & - & - & 1 & - & - & - & - \\
\hline & p24 & 42 & 88 & 1 & 131 & 8 & 6 & - & 14 & 8 & 6 & - & 14 \\
\hline & p2p7p1p6 & 6 & 18 & - & 24 & 2 & - & - & 2 & 2 & - & - & 2 \\
\hline & Total & 66 & 138 & 1 & 205 & 11 & 6 & - & 17 & 10 & 6 & 0 & 16 \\
\hline \multirow[t]{7}{*}{ Pol } & Gag-Pol & 1 & - & - & 1 & - & - & - & - & - & - & - & - \\
\hline & Protease & 8 & - & - & 8 & 1 & - & - & 1 & 1 & - & - & 1 \\
\hline & $\mathrm{RT}$ & 39 & 20 & 3 & 62 & 12 & 1 & - & 13 & 12 & 1 & - & 13 \\
\hline & RT- & & & & & & & & & & & & \\
\hline & Integrase & 1 & 1 & - & 2 & 1 & - & - & 1 & 1 & - & - & 1 \\
\hline & Integrase & 12 & 11 & - & 23 & 5 & 2 & - & 7 & 4 & 2 & - & 6 \\
\hline & Total & 61 & 32 & 3 & 96 & 19 & 3 & 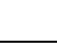 & 22 & 18 & 3 & 0 & 21 \\
\hline Vif & & 9 & 2 & - & 11 & - & - & - & - & - & - & - & - \\
\hline Vpr & & 7 & 6 & - & 13 & - & - & - & - & - & - & - & - \\
\hline Tat & & 4 & 6 & 1 & 11 & - & - & - & - & - & - & - & 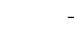 \\
\hline $\operatorname{Rev}$ & & 4 & 5 & - & 9 & - & - & - & - & - & - & - & - \\
\hline Vpu & & 1 & 1 & - & 2 & - & - & - & - & - & - & - & - \\
\hline Env & & 40 & 82 & 75 & 197 & - & - & 2 & 2 & - & - & 1 & 1 \\
\hline Nef & & 37 & 24 & 1 & 62 & 2 & 1 & - & 3 & 2 & 1 & - & 3 \\
\hline & Total & 229 & 296 & 81 & 606 & 32 & 10 & 2 & 44 & 30 & 10 & 1 & 41 \\
\hline
\end{tabular}

\# CTL epitopes included only the best-defined epitopes as described by Frahm et al. (2007) [56]

* Only those epitopes present in more than $75 \%$ of the reference sequences were considered as highly conserved and thus included in the association rule mining. 3 epitopes completely overlapping with other epitopes of same type without amino acid differences were not included.

$\wedge$ Associated epitopes are epitopes involved in association rules identified with a support value of 0.75 and confidence value of 0.95

sequences. Among them one CTL and two Th epitopes were completely overlapping with other epitopes of the same type without amino acid differences and, thus, were excluded from the association rule mining to avoid redundancy (e.g., the CTL epitope from the Gag gene VIPMFSAL overlaps with the CTL epitope EVIPMFSAL and is present in exactly the same reference sequences). Epitopes of different types that completely overlap with each other without amino acid differences were also included to take into account multi-functional regions (e.g., the CTL epitope KTAVQMAVF completely overlaps with the Th epitope LKTAVQMAVFIHNFK without amino acid differences). The final set of epitopes consisted of 44 epitopes representing 4 genes, namely, Gag, Pol, Env and Nef, and included $32 \mathrm{CTL}, 10 \mathrm{Th}$ and $2 \mathrm{Ab}$ epitopes (17 epitopes from Gag, 22 from Pol, 2 from Env and 3 from Nef) (Table 2).

\section{Identification of associated epitopes}

To identify frequently co-occurring epitopes of different types, we used association rule mining, a data mining technique that identifies and describes relationships (also referred to as associations or association rules) among items within a data set [66]. Although association rule mining is most often used in marketing analyses, such as "market basket" analysis $[67,68]$, this technique has been successfully applied to several biological problems (e.g., [69-71]), including discovery of highly conserved CTL epitopes [44].

The data on presence and absence of selected $44 \mathrm{epi-}$ topes in 90 reference sequences (as described above) was used as the input for the Apriori algorithm [67] implemented in the program WEKA [66,72]. Because of our focus on the highly conserved epitope associations, the minimum support was set at 0.75 to include only association rules present in at least $75 \%$ of the reference sequences. The confidence was set very high at 0.95 to generate only very strong associations, i.e., where epitopes co-occur in more than $95 \%$ of the sequences, and all generated association rules were exhaustively enumerated and examined. The maximum number of rules identified was set at 100000 to ensure that all association rules above the support and confidence thresholds are captured. Once identified, association rules that involved the same epitopes, but in different order, were "collapsed" into a single "unique" rule (i.e., A occurs with $B$ and $B$ occurs with $A$ are considered the same "unique" rule) [44].

Epitope-associations in a worldwide set of HIV-1 genomes To verify whether the association rules identified using a representative reference set reflect associations existing 


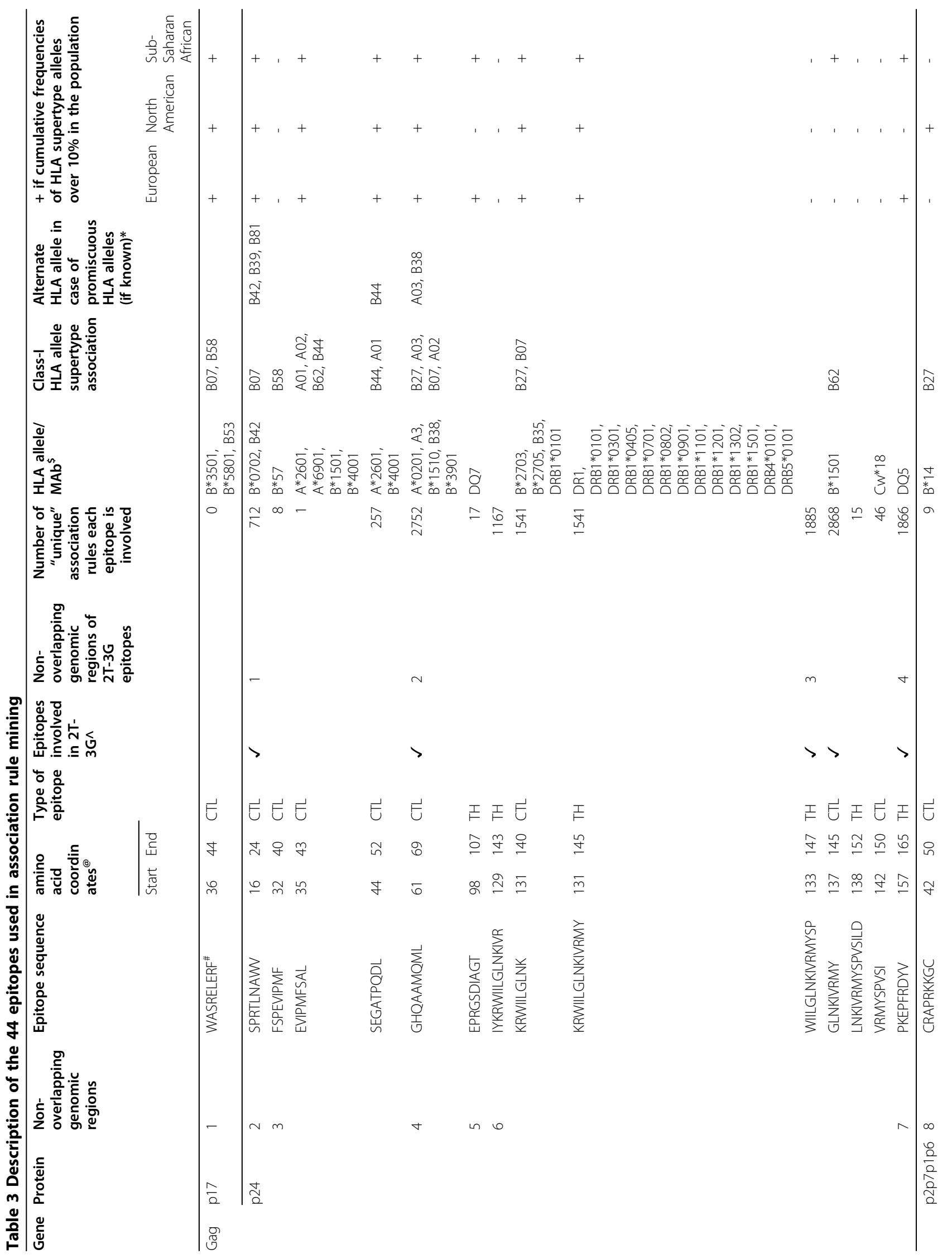




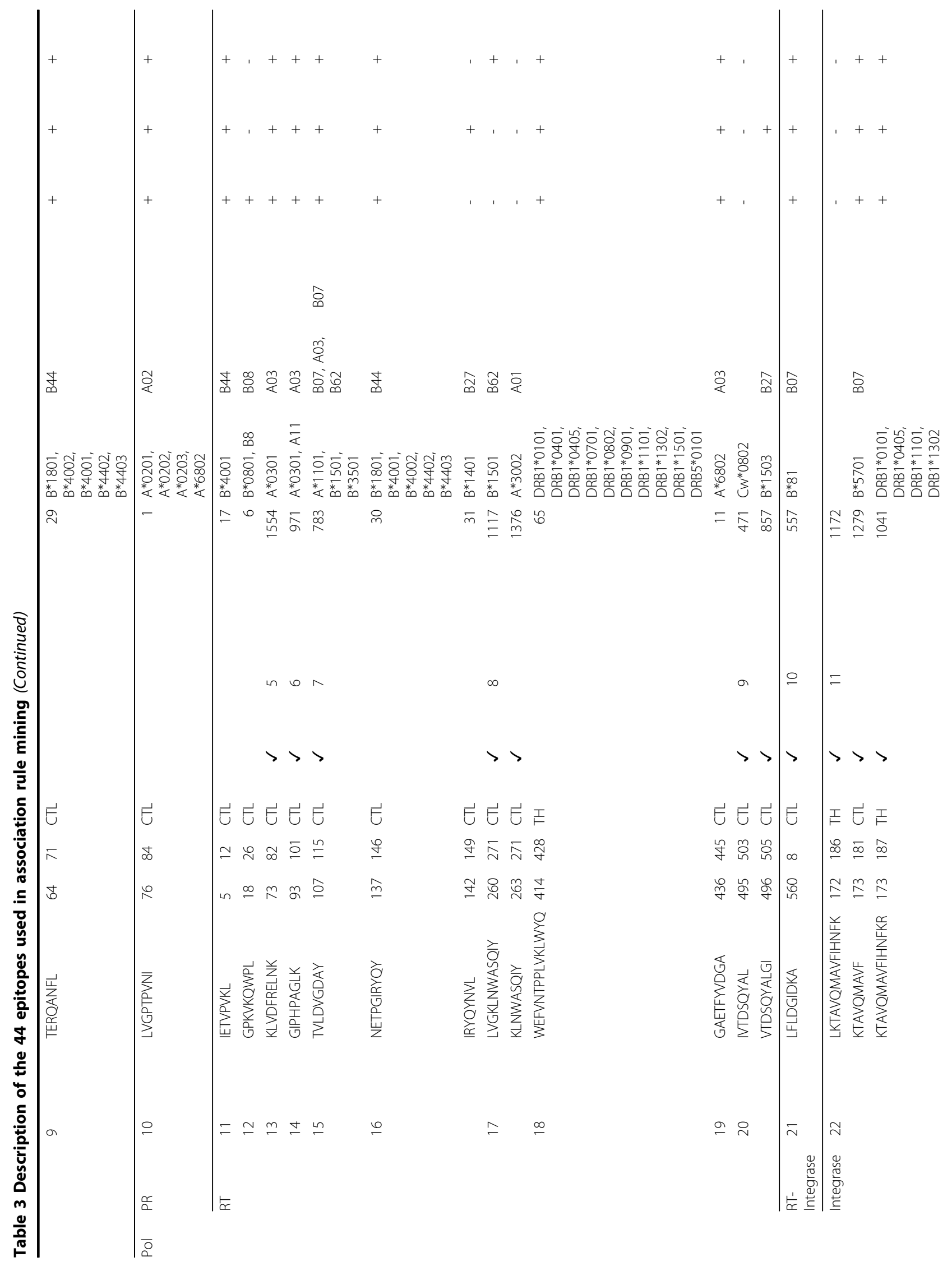




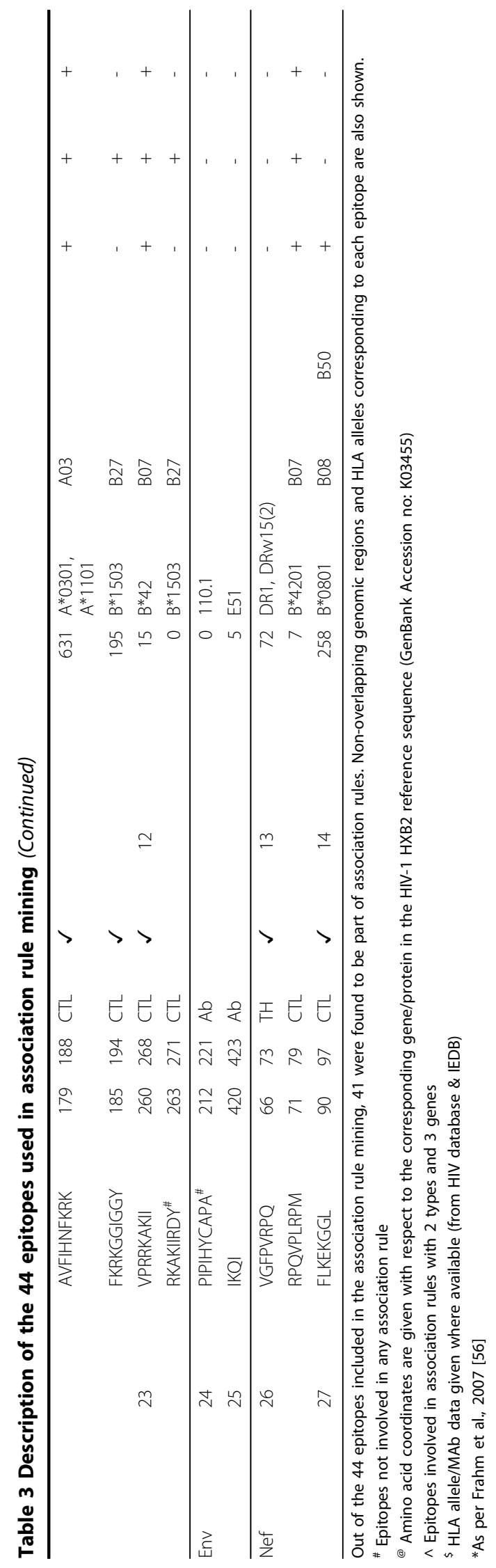

in a worldwide HIV-1 population, we examined a larger set of 978 HIV-1 sequences. This genome set included 888 HIV-1 sequences from the 2008 web alignment of the HIV Sequence database selected to include fulllength Gag, Pol and Nef genes for each genome, as well as 90 reference sequences used in the first steps of the analysis. The larger genome set included 650 sequences from the $\mathrm{M}$ group, 22 from the $\mathrm{N}$ and $\mathrm{O}$ groups and 306 recombinant sequences (Table 1, Additional file 3). An epitope-association was considered to be present in a particular genome only if all the epitopes participating in that association rule were present without any amino acid differences.

\section{Estimation of the nucleotide substitution rates}

To assess the extent of sequence divergence of associated epitopes, the number of synonymous nucleotide substitutions per synonymous site (dS) and the number of nonsynonymous nucleotide substitutions per nonsynonymous site $(\mathrm{dN})$ were estimated in 90 HIV-1 reference sequences. Each codon was classified as (i) non-epitope or as epitope region, if the codon was mapped to at least one type of epitope. The epitope regions were further subdivided into (ii) associated epitopes (i.e., epitopes participating in association rules), (iii) non-associated epitopes (i.e., those epitopes that were sufficiently conserved to be included in association rule mining but were not participating in association rules), and (iv) all other, variable, epitopes that were excluded from the association rule mining (i.e., those absent from more than $25 \%$ of sequences). Pairwise $d N$ and $d S$ values were estimated using the Nei-Gojobori method with the Jukes-Cantor correction [73]. This simple method was chosen because it is expected to have lower variance than more complicated substitution models [74]. The MEGA4 program [75] was used, and the standard errors were estimated with 500 bootstrap replications.

\section{Results}

\section{Discovery of epitope associations in 90 HIV-1 reference sequences}

Out of 606 epitopes included in the initial analyses, a total of 44 epitope regions, including $32 \mathrm{CTL}, 10 \mathrm{Th}$ and $2 \mathrm{Ab}$ epitopes, were present (as a perfect amino acid sequence match) in at least $75 \%$ of the 90 HIV-1 reference sequences and thus were included in the association rule mining. Using a high confidence value of $95 \%$ allowed us to focus only on the strongest association rules that involve the most frequently co-occurring epitopes. Using this stringent confidence cut-off, a total of 60626 associations involving three types of epitopes belonging to four genes, Gag, Pol, Env and Nef, were discovered, of them 6142 association rules were 
unique combinations of epitopes (Table 4). A total of 41 epitopes that belonged to 27 non-overlapping genomic regions from four genes were found to be involved in these association rules (Table 3 ). Figure 1 shows an example of an association rule involving four epitopes of two types (CTL and Th) and three genes ( Gag, Pol and Nef).

The majority of the unique epitope association rules (cumulatively comprising $>80 \%$ of all rules) involved only three to five epitopes, with the largest category comprised of rules with four epitopes (2098 associations), followed by 1719 associations with five and 1145 associations with three epitopes, respectively (Figure 2, Table 4). Notably, a significant number of association rules involved 6 to 8 epitopes (793 associations with six, 216 with seven and 31 with 8 epitopes, respectively). There were only two association rules in which 9 epitopes were involved. More details on number of associations based on epitope type and genes involved are given in Additional file 4. When gene locations were considered, over $82 \%$ of the unique epitope associations included epitopes from both the Gag and Pol genes, followed by $5.9 \%$ and $6.1 \%$ of associations involving only the Gag and only Pol genes, respectively. Another 5.4\% of unique association rules involved epitopes from the Nef gene, of which almost $60 \%$ of rules involved three genes, Gag, Pol and Nef, with the remainder distributed mostly between Gag-Nef and Pol-Nef associations (approximately $24 \%$ and 16\%, respectively). There were only five association rules that involved epitopes from the Env gene. Four of these five were from Gag-Env and one from Pol-Env associations. Notably, associations with antibody epitopes were limited to these five Env association rules, which can partially be attributed to the high degree of sequence divergence among the Env sequences that can differ by as much as $30 \%$ at the amino acid level [76].

No association rules included all three types of epitopes (CTL, Th and Ab) and four genes (Gag, Pol, Env and Nef). However, several "multi-type" association rules comprised of two different epitope types (CTL and Th) and three genes (Gag, Pol and Nef) were discovered (Figure 1, Additional file 5). For example, in the association rule: GHQAAMQML (CTL, Gag) - PKEPFRDYV (Th, Gag) - KLNWASQIY (CTL, Pol) - FLKEKGGL (CTL, Nef) (Figure 1), GHQAAMQML, KLNWASQIY and FLKEKGGL are CTL epitopes from the Gag, Pol and Nef genes, respectively, while PKEPFRDYV is a Th epitope from the Gag gene. Overall, there were 137 "multi-type" associations involving epitopes from two types and three genes (2T-3G) among a total of $21 \mathrm{CTL}$ and Th epitopes from the Gag, Pol and Nef genes (Additional file 5). These 21 epitopes can be mapped to 14 different non-overlapping genomic regions (Table 3) and a single association rule is generally spread across 3 to 5 of such regions. Interestingly, even though the association rule with the maximum number of epitopes in a single rule (9 epitopes) involved four non-overlapping genomic regions, it included epitopes from only two genes, Gag and Pol.

\section{Epitope-associations in the reference genome are representative of the global HIV-1 population}

Presence of association rules discovered in the reference genome set was verified by analyzing a larger worldwide set of $978 \mathrm{HIV}-1$ genomes (including 888 sequences from the 2008 web alignment and 90 reference sequences from the HIV Sequence database). The Gag, $\mathrm{Pol}$ and $\mathrm{Nef}$ genes in each sequence were concatenated for the purpose of the analysis, and presence of each association rule (as a complete match of all epitope regions involved) was noted. The results showed that most of the epitope-associations were present in the majority of genomes from the global HIV-1 population. In particular, out of 137 epitope associations involving two different types and three different genes (2T-3G), 134 association rules were present in more than $70 \%$ of the HIV-1 genomes (i.e., in > 685 sequences)

Table 4 Distribution of unique association rules according to genes involved in each association rule

\begin{tabular}{|c|c|c|c|c|c|c|c|c|c|c|}
\hline & Gag only & Pol only & Nef only & Gag-Pol & Gag-Env & Gag-Nef & Pol-Env & Pol-Nef & Gag-Pol-Nef & Total* \\
\hline Association rules with 2 epitopes & 46 & 24 & 1 & 55 & 3 & 5 & 1 & 3 & 0 & 138 \\
\hline Association rules with 3 epitopes & 104 & 160 & 0 & 768 & 1 & 33 & 0 & 23 & 56 & 1145 \\
\hline Association rules with 4 epitopes & 108 & 135 & 0 & 1699 & 0 & 29 & 0 & 23 & 104 & 2098 \\
\hline Association rules with 5 epitopes & 73 & 47 & 0 & 1551 & 0 & 11 & 0 & 4 & 33 & 1719 \\
\hline Association rules with 6 epitopes & 29 & 6 & 0 & 753 & 0 & 2 & 0 & 0 & 3 & 793 \\
\hline Association rules with 7 epitopes & 5 & 0 & 0 & 211 & 0 & 0 & 0 & 0 & 0 & 216 \\
\hline Association rules with 8 epitopes & 0 & 0 & 0 & 31 & 0 & 0 & 0 & 0 & 0 & 31 \\
\hline Association rules with 9 epitopes & 0 & 0 & 0 & 2 & 0 & 0 & 0 & 0 & 0 & 2 \\
\hline Total & 365 & 372 & 1 & 5070 & 4 & 80 & 1 & 53 & 196 & 6142 \\
\hline
\end{tabular}

* There were no epitope associations in the following categories: Env only, Nef-Env, Gag-Pol-Env, Gag-Nef-Env, Pol-Nef-Env, Gag-Pol-Env-Nef

$\$$ Detailed break-up of number of associations based on epitope type and genes involved is given in additional file 4 


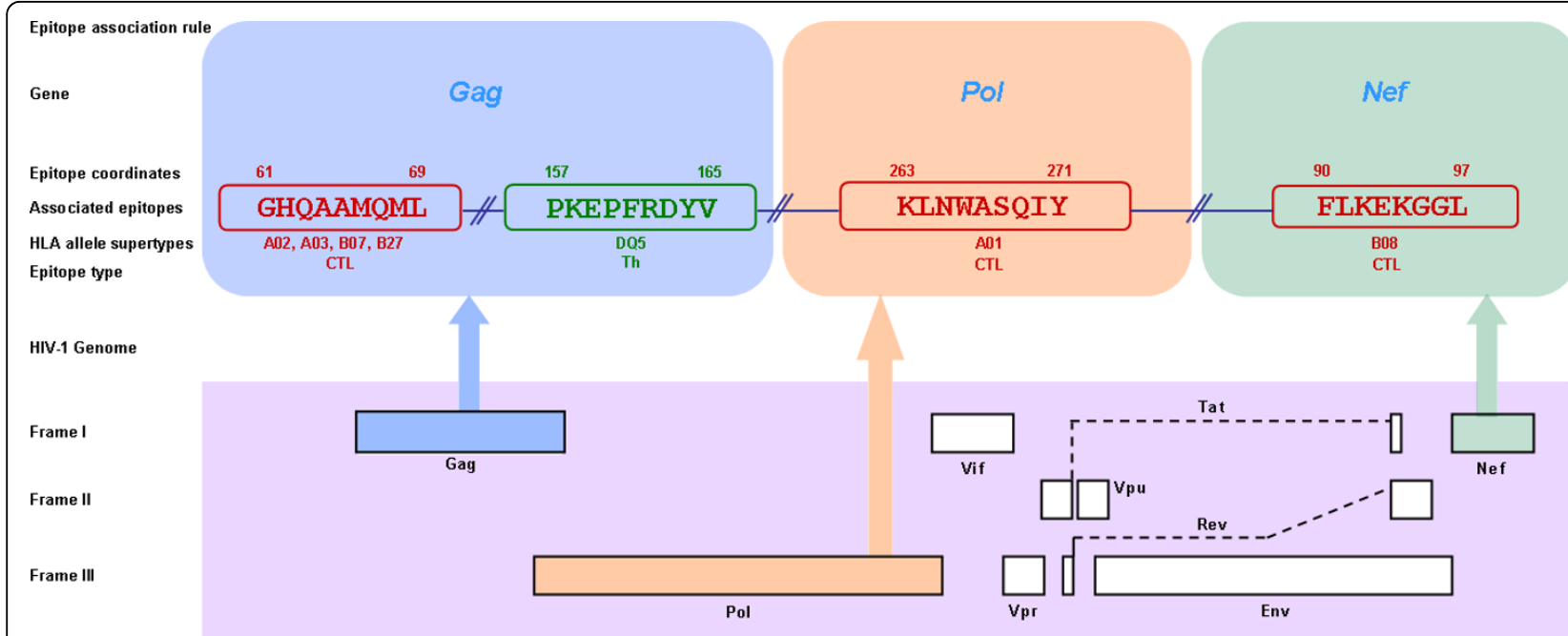

Figure 1 A "multi-type" association rule involving three CTL and one Th epitope from three different genes, Gag, Pol and Nef in reference to HIV-1 genome. The corresponding amino acid coordinates (as per HIV-1 HXB2 reference sequence) and HLA allele supertypes recognizing these epitopes are also shown.

(Additional file 6). Further, 978 sequences were also analyzed for the presence/absence of 21 individual epitopes participating in the $2 \mathrm{~T}-3 \mathrm{G}$ associations. The results revealed that with the exception of a single CTL epitope (VPRRKAKII from the Pol gene, present in 65\% of the sequences), all other epitopes were present in over $85 \%$ of the sequences (Additional file 7).

These results underscore the importance of these 21 highly conserved epitope regions, as reflected by their substantial presence across the global population of

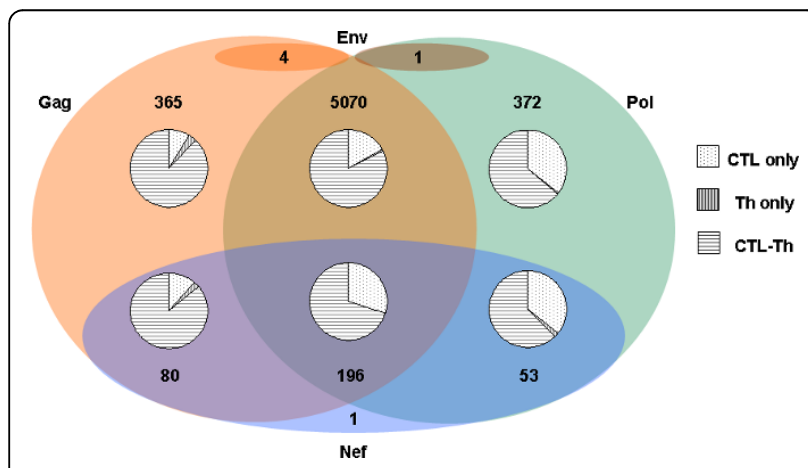

Figure 2 Relative composition of unique association rules involving multiple genes (Gag, Pol and Nef) and epitope types (Cytotoxic T Lymphocyte (CTL), T-Helper (Th) and antibody (Ab) epitopes). The 6142 unique association rules are classified according to the genes that harbor these epitopes. The pie-chart inside each segment represents the division according to the epitope region types involved. The single association rule in Nefonly category involved CTL and Th epitopes, while that in Pol-Env category involved CTL and Ab epitopes. Out of four association rules involving epitopes from Gag and Env, three belonged to CTL-Ab and one belonged to Th-Ab epitope regions types.
HIV-1. Notably, similar pattern of presence with high frequency was observed when the sets of $M$ group sequences (610), as well as sets of recombinant sequences (263), were considered separately. Interestingly, the latter group had these epitopes present in at least $80 \%$ of all sequences. On the other hand, only 7 out of the 21 epitopes were present in more than $75 \%$ of the sequences when the $\mathrm{N}$ and $\mathrm{O}$ groups were considered separately, which may reflect both the high degree of sequence divergence between $\mathrm{N}, \mathrm{O}$ and $\mathrm{M}$ groups [43,77], as well as that the majority of epitopes used here were discovered in M group sequences (HIV Molecular Immunology database, http://www.hiv.lanl. gov/content/immunology.

\section{Associated epitope regions are highly conserved at both amino acid and nucleotide levels}

To delineate selective forces affecting the evolution of different genomic regions in HIV-1 genomes, particularly those influencing epitope regions, the number of synonymous substitutions per synonymous site $(\mathrm{dS})$ and the number of nonsynonymous (amino acid altering) substitutions per nonsynonymous site $(\mathrm{dN})$ were estimated in all pairwise sequence comparisons of 90 reference genomes. Each codon was classified into one of four categories, either as (i) non-epitope, or as (ii) associated, (iii) nonassociated or (iv) variable epitope regions (see Methods section for details). Overall, in all pairwise sequence comparisons and different categories of epitope regions the number of synonymous substitutions per synonymous site significantly exceeded the number of nonsynonymous substitutions per nonsynonymous site, i.e., $d S>d N$ (paired t-test, $\mathrm{p}<0.001)$ (Table 5). This indicates that purifying 
Table 5 Nucleotide substitution rates among different epitope and non-epitope regions

\begin{tabular}{lccccc}
\hline & dN & SE $^{\#}$ & dS & SE & $\begin{array}{c}\text { P- } \\
\text { value* }\end{array}$ \\
\hline Associated epitopes & 0.01062 & 0.00952 & 0.20969 & 0.07091 & $<0.001$ \\
Non-associated epitopes & 0.02387 & 0.02537 & 0.24220 & 0.12666 & $<0.001$ \\
Not included epitopes & 0.10532 & 0.01277 & 0.29085 & 0.04305 & $<0.001$ \\
Non-epitopes & 0.09793 & 0.01653 & 0.27329 & 0.04665 & $<0.001$ \\
\hline
\end{tabular}

Average pairwise number of nonsynonymous $\left(d_{N}\right)$ and synonymous $\left(d_{S}\right)$ substitutions per nonsynonymous and synonymous site, respectively, estimated at different categories of epitope and non-epitope regions among reference sequences of $M$ group are given.

\# Standard errors were estimated with 100 bootstrap replications in MEGA4. * In pairwise t-tests, the null hypothesis of $\mathrm{dS}=\mathrm{dN}$ was rejected in all four comparisons.

selection plays a significant role in the evolution of HIV including evolution of the epitope regions, which is in agreement with our previous results $[44,78,79]$. Similar trend of overall $\mathrm{dS}>>\mathrm{dN}$ (paired t-test, $\mathrm{p}<0.001$ ) was also observed when sequences of the $\mathrm{N}$ and $\mathrm{O}$ groups were considered separately. However, because of the high degree of sequence divergence between the three groups due to their independent origin via separate cross-species transmission events [80-82], we will focus our discussion on the pairwise comparisons of the $\mathrm{M}$ group sequences only (including CRFs).

The average $\mathrm{dN}$ and $\mathrm{dS}$ values for each category of sites obtained from the pairwise comparisons of the reference sequences from the $M$ group are shown in Table 5. Notably, associated epitopes have significantly smaller $d N$ and $d S$ values than respective $d N$ and $d S$ values at other categories of sites, including nonepitopes (one-way ANOVA and nonparametric KruskalWallis tests, $\mathrm{p}<0.001$ ) (see also Additional file 8). While significantly lower $\mathrm{dN}$ values at associated epitopes can be attributed to strong purifying selection operating to reduce amino acid diversity at these highly conserved epitope regions, in agreement with our previous results $[44,78]$, the significantly lower dS values indicate that the high degree of sequence conservation exist not only at the amino acid level, but also at the nucleotide level in these associated regions. Notably, when we consider correlations between the levels of synonymous and nonsynonymous sequence divergence from different site categories for the same pair of sequences, relatively strong and statistically significant positive correlations (Pearson correlation coefficient values between 0.67 and $0.77, \mathrm{p}<0.01$ ) exist between $\mathrm{dN}$ and $\mathrm{dS}$ values for both non-epitope and epitope regions that were not included in the association rule mining, including variable epitopes, but not for associated epitopes. Similar trends are detected using nonparametric correlation (Kendall's tau values between 0.34 and $0.45, \mathrm{p}<0.001)$. This may be attributed to common factors (such as functional and structural constraints and mutation rate) influencing evolution of these regions, so that the regions with higher $\mathrm{dS}$ values are also likely to have higher $\mathrm{dN}$ values. On the other hand, the levels of synonymous and nonsynonymous sequence divergence at the associated epitopes have only weak or non-significant correlation both with each other $(r=-0.14, \mathrm{p}<0.01)$, as well as with $\mathrm{dN}$ and $\mathrm{dS}$ values at other regions within the same genomes (see Additional file 9). These results indicate that the lower $\mathrm{dS}$ values at the associated epitope regions are not merely the reflection of the overall lower mutation rates, but rather due to specific selective forces preserving nucleotide sequences in these regions, much like purifying selection operating to maintain amino acid sequences at the same epitopes. Although the exact nature of these selection constraints remains to be elucidated, it may be related with the structural constraints at the level of RNA structure, including potential regulatory RNA elements that are yet to be described in the HIV genome [83]. Interestingly, when the number of sites characterized as "structured" and "non-structured" in Watts et al. (2009) [83] study was compared among regions classified as associated epitopes and nonepitopes in this study, the results showed that associated epitope regions tend to harbor a significantly larger proportion of structured than non-structured sites while non-epitopes harbor more non-structured than structured sites (Fisher's exact test, $\mathrm{p}<0.05$ ). Because structured regions are expected to be more evolutionary conserved at the nucleotide level to preserve the ability to form secondary or higher-order RNA structures, this is consistent with the overall lower degree of sequence divergence observed among associated epitopes. However, no statistically significant difference was observed when the numbers of structured and unstructured sites were compared between associated epitopes and epitope regions not included in the association rule mining $(p>0.05)$. This can be attributed to a variety of factors, including that the latter epitope category is a heterogeneous mixture of epitopes that are evolving with different rates under different selection pressures $[78,79]$. Likewise, as pointed out by Watts et al. (2009) [83], while most structures in their studied HIV-1 model have been well characterized, some structural RNA elements may still require further refinement.

\section{Discussion}

Overall, our results identified a set of strong associations between CTL and T-Helper epitopes that co-occur in the majority of the HIV-1 genomes worldwide and can be considered strong candidates for multi-epitope vaccine and/or treatment targets. There have been several attempts to design multi-epitope vaccines using different 
strategies for the epitope selection, which is one of the most important steps in a multi-epitope vaccine design. Some studies have suggested computer based epitope prediction methods (e.g., [23,84-86]) for such selection, although accuracy of in-silico methods for "prediction of epitopes" is still debated [87]. It has been proposed that a mixture of epitopes representing variable regions or potential escape variants can be used to overcome enormous viral diversity of HIV (e.g., [88,89]). Indeed, some of the hypervariable regions have been shown to be strongly immunogenic eliciting broad cross-subtype-specific responses [90,91]. On the other hand, such highly variable regions may not account for critical functional or structural features of the virus, while epitopes that are highly conserved among different subtypes are likely to be of functional significance and thus less prone to escape mutations [28]. In either case, because of the dynamic nature of intra-patient HIV evolution, the need to achieve a broad immune response can be fulfilled through multi-gene/multi-type approach $[1,92]$, with T-Helper activity playing an important role alongside the CTL response (e.g., $[93,94]$ ).

Our results identified several association rules that not only involved two epitope types and three genes, but also were found in the vast majority of HIV-1 genomes analyzed. For instance, the association rule, GHQAAMQML (CTL, Gag) - PKEPFRDYV (Th, Gag) - KLNWASQIY (CTL, Pol) - FLKEKGGL (CTL, Nef) (Figure 1) was present in over $83.5 \%$ (818 sequences) of the worldwide HIV1 genomes analyzed. Among these, the epitope GHQAAMQML is restricted by HLA alleles from different supertypes, namely, B07 (B*38), B27 (B*1510, B*3901), A02 (A*0201) and A03 (A*03) while epitopes PKEPFRDYV, KLNWASQIY and FLKEKGGL are recognized by DQ5, A01 (A*3002) and B08 (B*0801) respectively. Notably, many of the associated epitopes harbor other epitopes as sub-sequences that are restricted by yet other set of HLA alleles, thus potentially expanding the breadth of epitope recognition across a broad range of host HLA alleles. For example, in the association rule involving epitopes GLNKIVRMY (CTL, Gag) - PKEPFRDYV (Th, Gag) LVGKLNWASQIY (CTL, Pol) - FLKEKGGL (CTL, Nef), epitope LVGKLNWASQIY includes another epitope, KLNWASQIY, as its sub-sequence. These two epitopes are recognized by alleles from different class I HLA loci, $B * 1501$ (B62) and A*3002 (A01), respectively. This not only increases the potential for recognition populationwide, but also increases the likelihood of this region being recognized within the same individual. Moreover, recent studies have shown promiscuous binding of CTL [95] and Th epitopes [96] in HIV-1, i.e., epitope presentation and $\mathrm{T}$-cell recognition may occur in the context of alternative HLA alleles different from the originally defined HLA alleles. This further enhances potential population coverage for recognition of the associated epitopes. It is worth noting that the involvement of Ab epitopes in association rules described here was quite limited, partly because of the strict presence/absence criteria used in the initial selection of epitopes and association rule mining, as well as the fact that the vast majority of Ab epitopes are located within $E n v$, a highly variable genomic region. Only five association rules included a combination of $\mathrm{Ab}$ and other epitope types (one Th-Ab, and four CTL-Ab associations). Further, this study did not include conformational epitopes, which form a large number of HIV-1 B cell epitopes. However, inclusion of a suitable Ab epitope should be considered alongside the associated CTL and Th epitopes, although further studies are needed to elucidate mechanisms of epitope association and interaction across different types and to identify the most promising Ab epitope candidates.

Although some individual epitopes have been previously identified as conserved (Additional file 10), lack of uniform criterion for defining conservation and use of different subsets of HIV sequences (and often only few subtypes) in different studies make it difficult to evaluate relative extent of sequence conservation. Thus, our study provides first comprehensive systematic survey of CTL, Th and Ab epitopes that are highly conserved and also co-occur together among all subtypes of HIV-1. There are several advantages of using multiple highly conserved epitopes from different genomic locations, such as those represented by association rules, in HIV vaccine. The highly conserved nature of amino acid sequences of these epitopes, along with the signature of strong purifying selection acting at the nucleotide level of the associated epitopes indicates that these associated regions represent functionally critical genomic regions, thus decreasing the likelihood of successful escape mutations. The reasons behind such conservation remain to be elucidated and may be driven by constraints acting on the viral genome itself or restraints due to virus-host interactions. It is likely that such persistently conserved residues indeed comprise structurally or functionally important elements critical for viral fitness, either due to interactions between the associated regions, or due to their involvement with the "outside" interactors. The latter possibility is indirectly supported by the appearance of compensatory mutations that accompany escape mutations and that may be located elsewhere in the protein sequence (e.g., $[97,98])$. Further, the structural constraints may also be driven by interactions between regions harboring associated epitopes, direct or indirect. For example, conserved 2T-3G epitopes SPRTLNAWV (CTL) and GHQAAMQML (CTL) from the 5' end of the Gag gene are involved in formation of the secondary structure elements, such as helix I and IV, of the p24 capsid protein [99]. Further, of 712 association rules that involve the former epitope, about $41.9 \%$ also include the latter epitope 
(with the remaining rules covering other parts of the HIV1 genome). Notably, helix I plays an important role in hexamerization of p24 during viral maturation [100] and mutations in that portion of the capsid often give rise to noninfectious viruses [99]. Likewise, the outside positioning of helix IV in the p24 hexameric ring as shown in Figure two of Li et al. (2000) [100] and PDB structure 3GV2 [101] suggests it may participate in protein-protein interactions. It is possible that associated epitopes are involved in RNA-protein interactions as well [102].

An additional advantage of using the associated epitopes is that even if escape mutations are successful at a particular region, the other regions can still be targeted. Moreover, because amino acid changes in these epitope regions are relatively rare, inclusion of these regions in a multi-epitope vaccine can not only provide protection against a broad variety of existing HIV-1 variants including many circulating recombinant forms, but can also offer some protection against the new strains that can arise in the near future. Most importantly, inclusion of epitopes that are immuno-responsive to different arms of the host immune machinery, such as CTL and Th epitope combinations can enable stronger and more efficient immune responses, similar to responses achieved with adjuvant therapies (e.g., $[45,48,49,103]$ ).

Thus, our study provides a unique strategy to identify suitable epitope candidates for multi-gene/multi-type vaccines that are both highly conserved across the global HIV-1 population and highly likely to co-occur together in the same viral genome in various HIV-1 subtypes and thus can be simultaneously targeted by multi-epitope vaccines. Some of these conserved epitopes have been included in several recently tested vaccine candidates that showed promising results; however, none have included associated epitopes from all three genes. For example, segments of Gag, Pol and Nef were included in the recent LIPO-5 lipopeptide vaccine trial that showed $\mathrm{T}$-cell responses in $50 \%$ of vaccines [104], yet it lacked associated epitopes from Pol (Additional file 11). Further, because the included epitopes are already derived from the lists of epitopes with experimentally demonstrated immunogenicity in humans, (e.g., the list of "best defined" CTL epitopes by Frahm et al., 2007 [56]), many challenges associated with the accuracy of computational epitope prediction (e.g., $[87,105,106])$ can be avoided. Moreover, while sequence conservation does not assure that the epitope will be strongly immunogenic (e.g., $[107,108])$, associated epitopes reported in this study also exhibit a high degree of nucleotide sequence conservation which is not readily identifiable by other tools, such as Epitope Conservancy Analysis Tool [107], making them suitable targets for other types of treatments such as RNA interference [109].

Notably, a high degree of amino acid sequence conservation is not the only factor that influences identification of epitopes as promising candidates. For example, several epitopes included in the association rule mining, namely, PIPIHYCAPA (Ab, Env), WASRELERF (CTL, Gag) and RKAKIIRDY (CTL, Pol), were not involved in any of the 60626 associations that we discovered, showing that high conservation at the amino acid level does not automatically translate into involvement in association rules and that other factors are also at play. While it is likely that associated epitopes are harbored in functionally or structurally important domains and thus experience strong constraints due to protein-protein or RNA-protein interactions [102,110-116], further comprehensive experimental and computational studies are needed to better understand the functional and structural constraints and mechanisms underlying the phenomenon of associated epitopes and evolutionary forces that shape sequence variability of these regions.

\section{Conclusions}

This study provides a comprehensive systematic survey of $\mathrm{CTL}, \mathrm{Th}$ and $\mathrm{Ab}$ epitopes that are both highly conserved and co-occur together among all subtypes of HIV-1, including circulating recombinant forms. Several cooccurring epitope combinations were identified as potent candidates for inclusion in multi-epitope vaccines, including epitopes that are immuno-responsive to different arms of the host immune machinery and can enable stronger and more efficient immune responses, similar to responses achieved with adjuvant therapies. Signature of strong purifying selection acting at the nucleotide level of the associated epitopes indicates that these regions are functionally critical, although the exact reasons behind such sequence conservation remain to be elucidated.

\section{Additional material}

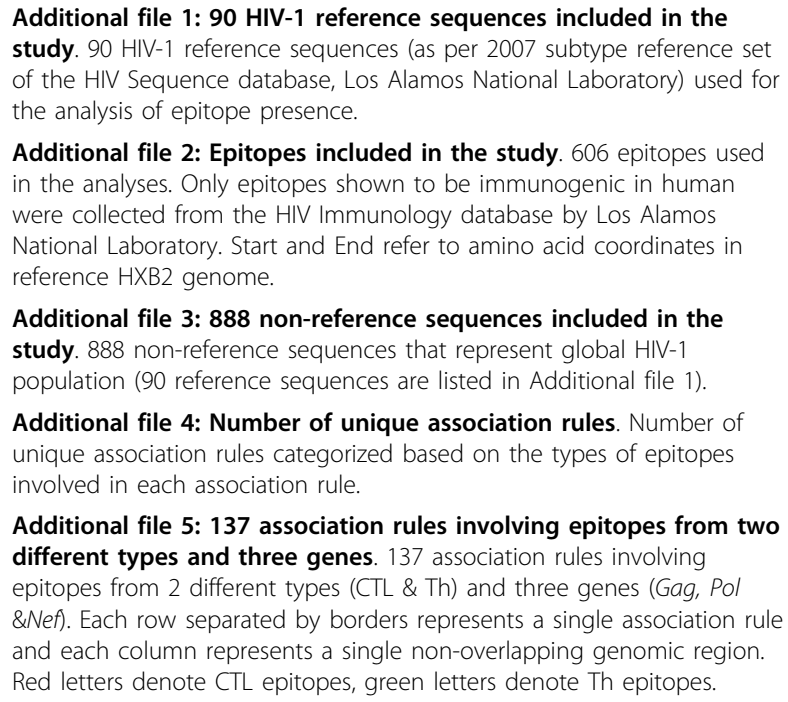

Additional file 3: $\mathbf{8 8 8}$ non-reference sequences included in the study. 888 non-reference sequences that represent global HIV-1 population (90 reference sequences are listed in Additional file 1).

Additional file 4: Number of unique association rules. Number of unique association rules categorized based on the types of epitopes involved in each association rule.

Additional file 5: 137 association rules involving epitopes from two different types and three genes. 137 association rules involving epitopes from 2 different types (CTL \& Th) and three genes (Gag, Pol \&Nef). Each row separated by borders represents a single association rule and each column represents a single non-overlapping genomic region. Red letters denote CTL epitopes, green letters denote Th epitopes. 
Epitopes on blue background are those from Gag gene, while those in tan and green backgrounds are from Pol and Nef genes, respectively.

Additional file 6: Subtype-wise frequencies of 137 2T-3G association rules. Subtype-wise frequencies of 137 unique association rules where epitopes from 3 genes and 2 types (2T-3G) are involved.

Additional file 7: Frequencies of 21 epitopes involved in 2T-3G association rules. Frequencies of 21 epitopes involved in $2 \mathrm{~T}-3 \mathrm{G}$ association rules in different groups of HIV-1 sequences used in the analysis

Additional file 8: Box-plot of $\mathrm{dN}$ and $\mathrm{dS}$ values at different categories of epitopes and non-epitopes. Box-plot of $d N$ and $d S$ values at different categories of epitopes and non-epitopes. P-values are based on t-tests, comparing respective values among site categories.

Additional file 9: Plots of pairwise $\mathrm{dN}$ and $\mathrm{dS}$ values between different genomic regions. Plots of pairwise $\mathrm{dN}$ and $\mathrm{dS}$ values between (a) Associated epitope regions (b) Variable epitopes that were not included in association rule mining and (c) Non-epitope regions for the M group HIV-1 genome. Noticeably, there were no correlation between $d N$ and $d S$ values from associated epitopes and respective $d N$ and $d S$ values from non-epitope regions or variable epitopes. On the other hand, $\mathrm{dN}$ and $\mathrm{dS}$ values were correlated between non-epitope regions and variable epitopes.

Additional file 10: List of 41 associated epitopes and references to published papers that reported epitopes as conserved and/or evidence of escape. List of 41 associated epitopes and respective references that have identified the epitope as conserved and/or provided evidence of escape. It should be noted that the epitope conservation criteria and sets of HIV-1 sequences used to define conserved epitopes varied from study to study

Additional file 11: List of associated epitopes and whether canonical epitope sequences were included in the recently tested vaccine candidates. List of associated epitopes and whether or not canonical epitope sequences were included in several recently tested vaccine candidates.

\section{Abbreviations}

Ab: Antibody; AIDS: Acquired Immunodeficiency Syndrome; CRFs: Circulating Recombinant Forms; CTL: Cytotoxic T-Lymphocyte; HAART: Highly Active Anti-Retroviral Therapy; HIV-1: Human Immunodeficiency Virus-1; HLA: Human Leukocyte Antigen; LANL: Los Alamos National Laboratory; MAb: Monoclonal Antibody; RNA: Ribonucleic Acid; Th: T-Helper

\section{Acknowledgements}

This work was partially supported by the Kent State University Research Council and NIH NIGMS grant GM86782-01A1 to HP.

\section{Authors' contributions}

SP did the analyses and wrote the manuscript. HP conceived and coordinated the study and wrote the manuscript. All authors read and approved the final manuscript.

\section{Competing interests}

The authors declare that they have no competing interests.

Received: 13 May 2010 Accepted: 9 August 2010

Published: 9 August 2010

\section{References}

1. Ross AL, Brave A, Scarlatti G, Manrique A, Buonaguro L: Progress towards development of an HIV vaccine: report of the AIDS Vaccine 2009 Conference. The Lancet Infectious Diseases 2010, 10(5):305-316.

2. Walensky RP, Paltiel AD, Losina E, Mercincavage LM, Schackman BR, Sax PE, Weinstein MC, Freedberg KA: The survival benefits of AIDS treatment in the United States. J Infect Dis 2006, 194(1):11-19.

3. Bedimo R, Chen RY, Accortt NA, Raper JL, Linn C, Allison JJ, Dubay J, Saag MS, Hoesley CJ: Trends in AIDS-defining and non-AIDS-defining malignancies among HIV-infected patients: 1989-2002. Clinical Infectious Diseases 2004, 39(9):1380-1384

4. Florescu D, Kotler DP: Insulin resistance, glucose intolerance and diabetes mellitus in HIV-infected patients. Antivir Ther 2007, 12(2):149-162.

5. Little SJ, Holte S, Routy JP, Daar ES, Markowitz M, Collier AC, Koup RA, Mellors JW, Connick E, Conway B: Antiretroviral-drug resistance among patients recently infected with HIV. N Engl J Med 2002, 347(6):385-394.

6. Chun TW, Engel D, Berrey MM, Shea T, Corey L, Fauci AS: Early establishment of a pool of latently infected, resting CD4 T cells during primary HIV-1 infection. Proceedings of the National Academy of Sciences 1998, 95(15):8869-8873.

7. Ross L, Lim ML, Liao Q, Wine B, Rodriguez AE, Weinberg W, Shaefer M: Prevalence of antiretroviral drug resistance and resistance-associated mutations in antiretroviral therapy-naive HIV-infected individuals from 40 United States cities. HIV Clinical Trials 2007, 8(1):1-8.

8. Clavel F, Hance AJ: HIV drug resistance. N Engl J Med 2004, 350(10):1023-1035

9. Hutter G, Nowak D, Mossner M, Ganepola S, Mussig A, Allers K, Schneider T, Hofmann J, Kucherer C, Blau O: Long-term control of HIV by CCR5 Delta32/Delta32 stem-cell transplantation. N Engl J Med 2009, 360(7):692-698.

10. Cohen J: HIV/AIDS research. Surprising AIDS vaccine success praised and pondered. Science 2009, 326(5949):26-27.

11. Rerks-Ngarm S, Pitisuttithum P, Nitayaphan S, Kaewkungwal J, Chiu J, Paris R, Premsri N, Namwat C, de Souza M, Adams E: Vaccination with ALVAC and AIDSVAX to Prevent HIV-1 Infection in Thailand. N Engl J Med 2009, 361(23):2209-2220

12. Cohen J: Beyond Thailand: Making Sense of a Qualified AIDS Vaccine" Success". Science 2009, 326(5953):652-653

13. Fauci AS, Johnston Ml, Dieffenbach CW, Burton DR, Hammer SM, Hoxie JA, Martin M, Overbaugh J, Watkins DI, Mahmoud A: HIV vaccine research: the way forward. Science 2008, 321(5888):530-532.

14. Deeks $S$, Walker B: The immune response to AIDS virus infection: good, bad, or both? J Clin Invest 2004, 113(6):808-810.

15. Pantaleo G, Koup RA: Correlates of immune protection in HIV-1 infection: what we know, what we don't know, what we should know. Nat Med 2004, 10:806-810.

16. Meddows-Taylor S, Papathanasopoulos MA, Kuhn L, Meyers TM, Tiemessen CT: Detection of Human Immunodeficiency Virus Type 1 Envelope Peptide-Stimulated T-helper Cell Responses and Variations in the Corresponding Regions of Viral Isolates among Vertically Infected Children. Virus Genes 2004, 28(3):311-318.

17. Schutten M, Langedijk JPM, Andeweg AC, Huisman RC, Meloen RH, Osterhaus A: Characterization of a V3 domain-specific neutralizing human monoclonal antibody that preferentially recognizes nonsyncytium-inducing human immunodeficiency virus type 1 strains. J Gen Virol 1995, 76(7):1665-1673.

18. Takeshita T, Takahashi H, Kozlowski S, Ahlers JD, Pendleton CD, Moore RL, Nakagawa Y, Yokomuro K, Fox BS, Margulies DH: Molecular analysis of the same HIV peptide functionally binding to both a class I and a class II MHC molecule. The Journal of Immunology 1995, 154(4):1973-1986.

19. Nakamura Y, Kameoka M, Tobiume M, Kaya M, Ohki K, Yamada T, Ikuta K: A chain section containing epitopes for cytotoxic $T, B$ and helper $T$ cells within a highly conserved region found in the human immunodeficiency virus type $1 \mathrm{Gag}$ protein. Vaccine 1997, 15(5):489-496.

20. McMichael AJ, Phillips RE: Escape of Human Immunodeficiency Virus from immune control. Annu Rev Immunol 1997, 15(1):271-296.

21. Jin X, Newman MJ, De-Rosa S, Cooper C, Thomas E, Keefer M, Fuchs J, Blattner W, Livingston BD, McKinney DM: A novel HIV T helper epitopebased vaccine elicits cytokine-secreting HIV-specific CD4 T cells in a Phase I clinical trial in HIV-uninfected adults. Vaccine 2009, 27:7080-7086.

22. Nehete PN, Chitta S, Hossain MM, Hill L, Bernacky BJ, Baze W, Arlinghaus RB, Sastry K: Protection against chronic infection and AIDS by an HIV envelope peptide-cocktail vaccine in a pathogenic SHIV-rhesus model. Vaccine 2001, 20(5-6):813-825

23. Sette A, Fikes J: Epitope-based vaccines: an update on epitope identification, vaccine design and delivery. Curr Opin Immunol 2003, 15(4):461-470.

24. Spearman $P$, Kalams S, Elizaga M, Metch B, Chiu YL, Allen M, Weinhold KJ Ferrari G, Parker SD, McElrath MJ: Safety and immunogenicity of a CTL 
multiepitope peptide vaccine for HIV with or without GM-CSF in a phase I trial. Vaccine 2009, 27:243-249.

25. Klein J, Horejsi V: Immunology. Oxford, UK: Blackwell Science 1997.

26. Goulder P, Price D, Nowak M, Rowland-Jones S, Phillips R, McMichael A: Coevolution of human immunodeficiency virus and cytotoxic T-lymphocyte responses. Immunol Rev 1997, 159:17-29.

27. Koenig S, Conley AJ, Brewah YA, Jones GM, Leath S, Boots LJ, Davey V, Pantaleo G, Demarest JF, Carter C: Transfer of HIV-1-specific cytotoxic T lymphocytes to an AIDS patient leads to selection for mutant HIV variants and subsequent disease progression. Nat Med 1995, 1(4):330-336.

28. Jones NA, Wei X, Flower DR, Wong M, Michor F, Saag MS, Hahn BH, Nowak MA, Shaw GM, Borrow P: Determinants of human immunodeficiency virus type 1 escape from the primary CD8+ cytotoxic T lymphocyte response. J Exp Med 2004, 200(10):1243-1256.

29. Doherty PC, Turner SJ: Q\&A: What do we know about influenza and what can we do about it? J Biol 2009, 8(5):46.

30. O'Connor DH, McDermott AB, Krebs KC, Dodds EJ, Miller JE, Gonzalez EJ, Jacoby TJ, Yant L, Piontkivska H, Pantophlet R: A Dominant Role for CD8 -T-Lymphocyte Selection in Simian Immunodeficiency Virus Sequence Variation. J Virol 2004, 78(24):14012-14022.

31. Ross HA, Rodrigo AG: Immune-mediated positive selection drives human immunodeficiency virus type 1 molecular variation and predicts disease duration. J Virol 2002, 76(22):11715-11720.

32. Timm J, Lauer GM, Kavanagh DG, Sheridan I, Kim AY, Lucas M, Pillay T, Ouchi K, Reyor LL, zur Wiesch JS: CD8 Epitope Escape and Reversion in Acute HCV Infection. J Exp Med 2004, 200(12):1593-1604.

33. Newman MJ, Livingston B, McKinney DM, Chesnut RW, Sette A, Subsetsimmunology TL: T-lymphocyte epitope identification and their use in vaccine development for HIV-1. Front Biosci 2002, 7:d1503-1515.

34. Gahery-Segard H, Pialoux G, Charmeteau B, Sermet S, Poncelet H, Raux M, Tartar A, Levy JP, Gras-Masse H, Guillet JG: Multiepitopic B-and T-cell responses induced in humans by a human immunodeficiency virus type 1 lipopeptide vaccine. J Virol 2000, 74(4):1694-1703.

35. Duarte Cano CA: The multi-epitope polypeptide approach in HIV-1 vaccine development. Genet Anal: Biomol Eng 1999, 15(3-5):149-153.

36. Newman M, Livingston B, McKinney $D$, Chesnut $R$, Sette $A$ : The MultiEpitope Approach to Development of HIV Vaccines [abstract]. AIDS Vaccine 2001, No:35.

37. Rambaut A, Posada D, Crandall KA, Holmes EC: The causes and consequences of HIV evolution. Nature Reviews Genetics 2004, 5(1):52-61.

38. Thomson MM: HIV-1 Genetic Diversity and Its Biological Significance. HIV and the Brain: New Challenges in the Modern Era New York: Humana PressPaul RH, Sacktor ND, Valcour V, Tashima KT 2009, 267-291.

39. Jetzt $A E, Y u H$, Klarmann GJ, Ron Y, Preston BD, Dougherty JP: High rate of recombination throughout the human immunodeficiency virus type 1 genome. J Virol 2000, 74(3):1234-1240.

40. Robertson DL, Hahn BH, Sharp PM: Recombination in AIDS viruses. J Mol Evol 1995, 40(3):249-259

41. Zhuang J, Jetzt AE, Sun $G, Y u H$, Klarmann G, Ron Y, Preston BD, Dougherty JP: Human immunodeficiency virus type 1 recombination: rate, fidelity, and putative hot spots. J Virol 2002, 76(22):11273-11282.

42. Hughes AL, Westover K, da Silva J, O'Connor DH, Watkins DI: Simultaneous positive and purifying selection on overlapping reading frames of the tat and vpr genes of simian immunodeficiency virus. Journal of virology 2001, 75(17):7966-72.

43. Korber B, Gaschen B, Yusim K, Thakallapally R, Kesmir C, Detours V: Evolutionary and immunological implications of contemporary HIV-1 variation. Br Med Bull 2001, 58(1):19-42.

44. Paul S, Piontkivska H: Discovery of novel targets for multi-epitope vaccines: Screening of HIV-1 genomes using association rule mining. Retrovirology 2009, 6:62.

45. Berzofsky J: Development of artificial vaccines against HIV using defined epitopes. The FASEB Journal 1991, 5(10):2412-2418.

46. Johnston MI, Fauci AS: An HIV vaccine-evolving concepts. N Engl J Med 2007, 356(20):2073-2081.

47. Robinson HL, Montefiori DC, Villinger F, Robinson JE, Sharma S, Wyatt LS, Earl PL, McClure HM, Moss B, Amara RR: Studies on GM-CSF DNA as an adjuvant for neutralizing $A b$ elicited by a DNA/MVA immunodeficiency virus vaccine. Virology 2006, 352(2):285-294.

48. Shirai M, Pendleton CD, Ahlers J, Takeshita T, Newman M, Berzofsky JA: Helper-cytotoxic $T$ lymphocyte $(C T L)$ determinant linkage required for priming of anti-HIV CD8 CTL in vivo with peptide vaccine constructs. The Journal of Immunology 1994, 152(2):549-556.

49. Gram GJ, Karlsson I, Agger EM, Andersen P, Fomsgaard A: A Novel Liposome-Based Adjuvant CAF01 for Induction of CD8 Cytotoxic TLymphocytes (CTL) to HIV-1 Minimal CTL Peptides in HLA-A* 0201 Transgenic Mice. PLoS One 2009, 4(9):e6950.

50. Li B, Gladden AD, Altfeld M, Kaldor JM, Cooper DA, Kelleher AD, Allen TM: Rapid reversion of sequence polymorphisms dominates early human immunodeficiency virus type 1 evolution. J Virol 2007, 81(1):193-201.

51. Leitner T, Korber B, Daniels M, Calef C, Foley B: HIV-1 subtype and circulating recombinant form (CRF) reference sequences, 2005. HIV sequence compendium 2005, 2005:41-48

52. Carr JK, Foley BT, Leitner T, Salminen M, Korber B, McCutchan F: Reference sequences representing the principle genetic diversity of HIV-1 in the Pandemic. Human retroviruses and AIDS 1998 Los Alamos, NM: Theoretical Biology and Biophysics Group, Los Alamos National LaboratoryKorber B, Kuiken CL, Foley B, Hahn B, McCutchan F, Mellors JW, Sodroski J 1998, III:10-19.

53. Robertson DL, Anderson JP, Bradac JA, Carr JK, Foley B, Funkhouser RK, Gao F, Hahn BH, Kuiken C, Learn GH, Leitner T, McCutchan F, Osmanov S, Peeters M, Pieniazek D, Kalish ML, Salminen M, Sharp PM, Wolinsky S, Korber B: HIV-1 nomenclature proposal. Human Retroviruses and AIDS 1999 Los Alamos, NM: Theoretical Biology and Biophysics Group, Los Alamos National LaboratoryKuiken CL, Foley B, Hahn B, Korber B, McCutchan F, Marx PA, Mellors JW, Mullins JI, Sodroski J, Wolinsky S 1999, 492-505.

54. Kuiken C, Korber B, Shafer RW: HIV sequence databases. AIDS reviews 2003, 5(1):52-61.

55. Davies MN, Guan P, Blythe MJ, Salomon J, Toseland CP, Hattotuwagama C, Walshe $V$, Doytchinova IA, Flower DR: Using databases and data mining in vaccinology. Expert Opinion on Drug Discovery 2007, 2(1):19-35.

56. Frahm N, Linde C, Brander C: Identification of HIV-derived, HLA class I restricted CTL epitopes: insights into TCR repertoire, CTL escape and viral fitness. HIV molecular immunology 2006, 2007:3-28.

57. Korber B, Gnanakaran S: The implications of patterns in HIV diversity for neutralizing antibody induction and susceptibility. Current Opinion in HIV and AIDS 2009, 4(5):408-417.

58. Zolla-Pazner S, Cardozo T: Structure-function relationships of HIV-1 envelope sequence-variable regions refocus vaccine design. Nature Reviews Immunology 2010, 10(7):527-535.

59. Sette A, Peters B: Immune epitope mapping in the post-genomic era: lessons for vaccine development. Curr Opin Immunol 2007, 19(1):106-110

60. Malherbe L: T-cell epitope mapping. Annals of Allergy, Asthma and Immunology 2009, 103(1):76-79.

61. Gorny MK, Gianakakos V, Sharpe S, Zolla-Pazner S: Generation of human monoclonal antibodies to human immunodeficiency virus. Proceedings of the National Academy of Sciences 1989, 86(5):1624-1628.

62. Grimison B, Laurence J: Immunodominant epitope regions of HIV-1 reverse transcriptase: correlations with HIV-1 serum IgG inhibitory to polymerase activity and with disease progression. JAIDS J Acquired Immune Defic Syndromes 1995, 9(1):58-68.

63. Kanduc D, Serpico R, Lucchese A, Shoenfeld Y: Correlating low-similarity peptide sequences and HIV B-cell epitopes. Autoimmun Rev 2008, 7(4):291-296.

64. Noonan DM, Gringeri A, Meazza R, Rosso O, Mazza S, Muça-Perja M, Le Buanec $H$, Accolla RS, Albini A, Ferrini S: Identification of immunodominant epitopes in inactivated Tat-vaccinated healthy and HIV-1-infected volunteers. JAIDS J Acquired Immune Defic Syndromes 2003 33(1):47-55.

65. Yamada T, Iwamoto A: Expression of a novel Nef epitope on the surface of HIV type 1-infected cells. AIDS Res Hum Retroviruses 1999, 15(11):1001-1009.

66. Witten $\mathrm{H}$, Frank E: Data mining: practical machine learning tools and techniques San Francisco: Morgan Kaufmann 2005.

67. Agrawal R, Imieliński T, Swami A: Mining association rules between sets of items in large databases. Proceedings of the ACM SIGMOD International Conference on Management of Data: 26-28 May 1993; Washington, DC ACM PressPeter Buneman, Sushil Jajodia 1993, 207-216.

68. Chen MC, Wu HP: An association-based clustering approach to order batching considering customer demand patterns. Omega 2005, 33(4):333-343. 
69. Srisawat A, Kijsirikul B: Using associative classification for predicting HIV-1 drug resistance. Proceedings of the Fourth International Conference on Hybrid Intelligent Systems: 5-8 December 2004; Kitakyushu, Japan. IEEE Computer Society 2005, 280-284.

70. Yardımcı GG, Küçükural A, Saygın Y, Sezerman U: Modified Association Rule Mining Approach for the MHC-Peptide Binding Problem. Lecture Notes in Computer Science 2006, 4263:165-173.

71. Tamura M, D'haeseleer P: Microbial genotype-phenotype mapping by class association rule mining. Bioinformatics 2008, 24(13):1523-1529.

72. Frank $E$, Hall $M$, Trigg $L$, Holmes $G$, Witten $I H$ : Data mining in bioinformatics using Weka. Bioinformatics 2004, 20(15):2479-2481.

73. Nei M, Gojobori T: Simple methods for estimating the numbers of synonymous and nonsynonymous nucleotide substitutions. Mol Biol Evol 1986, 3(5):418-426.

74. Nei M, Kumar S: Molecular evolution and phylogenetics New York: Oxford University Press 2000.

75. Tamura K, Dudley J, Nei M, Kumar S: MEGA4: molecular evolutionary genetics analysis (MEGA) software version 4.0. Mol Biol Evol 2007, 24(8):1596-1599.

76. Gaschen B, Taylor J, Yusim K, Foley B, Gao F, Lang D, Novitsky V, Haynes B, Hahn BH, Bhattacharya T: Diversity considerations in HIV-1 vaccine selection. Science 2002, 296(5577):2354-2360.

77. Gao F, Bailes E, Robertson DL, Chen Y, Rodenburg CM, Michael SF, Cummins LB, Arthur LO, Peeters M, Shaw GM: Origin of HIV-1 in Pan troglodytes troglodytes. Nature 1999, 397(6718):436-441.

78. Piontkivska H, Hughes AL: Between-Host Evolution of Cytotoxic TLymphocyte Epitopes in Human Immunodeficiency Virus Type 1: an Approach Based on Phylogenetically Independent Comparisons. J Virol 2004, 78(21):11758-11765.

79. Piontkivska $H$, Hughes AL: Patterns of sequence evolution at epitopes for host antibodies and cytotoxic T-lymphocytes in human immunodeficiency virus type 1. Virus Res 2006, 116(1-2):98-105.

80. De Leys $R$, Vanderborght B, Vanden Haesevelde $M$, Heyndrickx L, Van Geel A, Wauters C, Bernaerts R, Saman E, Nijs P, Willems B: Isolation and partial characterization of an unusual human immunodeficiency retrovirus from two persons of west-central African origin. J Virol 1990, 64(3):1207-1216

81. Sharp PM, Bailes E, Chaudhuri RR, Rodenburg CM, Santiago MO, Hahn BH: The origins of acquired immune deficiency syndrome viruses: where and when? Philosophical Transactions: Biological Sciences 2001, 356:867-876.

82. Simon F, Mauclère $P$, Roques $P$, Loussert-Ajaka I, Müller-Trutwin MC, Saragosti S, Georges-Courbot MC, Barré-Sinoussi F, Brun-Vézinet F: Identification of a new human immunodeficiency virus type 1 distinct from group M and group O. Nat Med 1998, 4(9):1032-1037.

83. Watts JM, Dang KK, Gorelick RJ, Leonard CW, Bess JW Jr, Swanstrom R, Burch $C L$, Weeks KM: Architecture and secondary structure of an entire HIV-1 RNA genome. Nature 2009, 460(7256):711-716.

84. Khan AM, Miotto O, Heiny A, Salmon J, Srinivasan K, Nascimento EJM, Marques ETA, Brusic V, Tan TW, August JT: A systematic bioinformatics approach for selection of epitope-based vaccine targets. Cell Immunol 2006, 244(2):141-147

85. Yang $X, Y u X$ : An introduction to epitope prediction methods and software. Rev Med Virol 2008, 19:77-96.

86. Sette A, Livingston B, McKinney D, Appella E, Fikes J, Sidney J, Newman M, Chesnut $R$ : The development of multi-epitope vaccines: epitope identification, vaccine design and clinical evaluation. Biologicals 2001, 29(3-4):271-276

87. Bryson CJ, Jones TD, Baker MP: Prediction of Immunogenicity of Therapeutic Proteins: Validity of Computational Tools. BioDrugs 2010, 24(1):1-8.

88. Anderson DE, Malley A, Benjamini E, Gardner MB, Torres JÈV: Hypervariable epitope constructs as a means of accounting for epitope variability. Vaccine 1994, 12(8):736-740.

89. O'Connor D, Allen T, Watkins DI: Vaccination with CTL epitopes that escape: an alternative approach to HIV vaccine development? Immunol Lett 2001, 79(1-2):77-84.

90. Carlos MP, Anderson DE, Gardner MB, Torres JV: Immunogenicity of a vaccine preparation representing the variable regions of the HIV type 1 envelope glycoprotein. AIDS Res Hum Retroviruses 2000, 16(2):153-161.

91. Azizi A, Anderson DE, Torres JV, Ogrel A, Ghorbani M, Soare C, Sandstrom P, Fournier J, Diaz-Mitoma F: Induction of broad cross-subtype-specific HIV-1 immune responses by a novel multivalent HIV-1 peptide vaccine in cynomolgus macaques. The Journal of Immunology 2008, 180(4):2174-2186.

92. Rollman E, Bråve A, Boberg A, Gudmundsdotter L, Engström $G$, Isaguliants $M$, Ljungberg $K$, Lundgren B, Blomberg P, Hinkula J: The rationale behind a vaccine based on multiple HIV antigens. Microb Infect 2005, 7(14):1414-1423.

93. Ramduth D, Day CL, Thobakgale CF, Mkhwanazi NP, De Pierres C, Reddy S, Van Der Stok M, Mncube Z, Nair K, Moodley ES: Immunodominant HIV-1 CD4 T cell epitopes in chronic untreated clade C HIV-1 infection. PLOS One 2009, 4(4):e5013.

94. Ribeiro S, Rosa D, Fonseca S, Mairena E, Postól E, Ostrowski MA: A Vaccine Encoding Conserved Promiscuous HIV CD4 Epitopes Induces Broad T Cell Responses in Mice Transgenic to Multiple Common HLA Class II Molecules. PLOS ONE 2010, 5(6):e11072.

95. Frahm N, Yusim K, Suscovich TJ, Adams S, Sidney J, Hraber P, Hewitt HS, Linde $\mathrm{CH}$, Kavanagh DG, Woodberry T, Henry LM, Faircloth K, Listgarten J, Kadie C, Jojic N, Sango K, Brown NV, Pae E, Zaman MT, Bihl F, Khatri A, John M, Mallal S, Marincola FM, Walker BD, Sette A, Heckerman D, Korber BT, Brander C: Extensive HLA class I allele promiscuity among viral CTL epitopes. Eur J Immunol 2007, 37(9):2419-2433.

96. Kaufmann DE, Bailey PM, Sidney J, Wagner B, Norris PJ, Johnston MN, Cosimi LA, Addo MM, Lichterfeld M, Altfeld M: Comprehensive analysis of human immunodeficiency virus type 1-specific CD4 responses reveals marked immunodominance of gag and nef and the presence of broadly recognized peptides. J Virol 2004, 78(9):4463-4477.

97. Schneidewind A, Brockman MA, Sidney J, Wang YE, Chen H, Suscovich TJ, Li B, Adam Rl, Allgaier RL, Mothe BR: Structural and functional constraints limit options for cytotoxic T-lymphocyte escape in the immunodominant HLA-B27-restricted epitope in human immunodeficiency virus type 1 capsid. J Virol 2008, 82(11):5594-5605.

98. Wang YE, Li B, Carlson JM, Streeck H, Gladden AD, Goodman R, Schneidewind A, Power KA, Toth I, Frahm N: Protective HLA Class I Alleles That Restrict Acute-Phase CD8 T-Cell Responses Are Associated with Viral Escape Mutations Located in Highly Conserved Regions of Human Immunodeficiency Virus Type 1. J Virol 2009, 83(4):1845-1855.

99. Gitti RK, Lee BM, Walker J, Summers MF, Yoo S, Sundquist WI: Structure of the amino-terminal core domain of the HIV-1 capsid protein. Science 1996, 273(5272):231-235

100. Li S, Hill CP, Sundquist WI, Finch JT: Image reconstructions of helical assemblies of the HIV-1 CA protein. Nature 2000, 407(6802):409-413.

101. Pornillos O, Ganser-Pornillos BK, Kelly BN, Hua Y, Whitby FG, Stout CD Sundquist WI, Hill CP, Yeager M: X-ray structures of the hexameric building block of the HIV capsid. Cell 2009, 137(7):1282-1292.

102. Hagan NA, Fabris D: Dissecting the Protein-RNA and RNA-RNA Interactions in the Nucleocapsid-mediated Dimerization and Isomerization of HIV-1 Stemloop 1. J Mol Biol 2007, 365(2):396-410.

103. Ahlers JD, Dunlop N, Alling DW, Nara PL, Berzofsky JA: Cytokine-inadjuvant steering of the immune response phenotype to HIV-1 vaccine constructs: granulocyte-macrophage colony-stimulating factor and TNFalpha synergize with IL-12 to enhance induction of cytotoxic T lymphocytes. The Journal of Immunology 1997, 158(8):3947-3958.

104. Salmon-Ceron D, Durier C, Desaint C: OA04-01. Safety and immunogenicity of LIPO-5, a HIV-1 lipopeptide vaccine: results of ANRS VAC18, a phase 2, randomized, double-blind, placebo-controlled trial. Retrovirology 2009, 6(Suppl 3):O25.

105. MacNamara A, Kadolsky U, Bangham CRM, Asquith B: T-Cell Epitope Prediction: Rescaling Can Mask Biological Variation between MHC Molecules. PLoS Computational Biology 2009, 5(3):e1000327.

106. Reimer U: Prediction of Linear B-cell Epitopes. Methods in Molecular Biology Totowa, USA: Humama PressReineke U, Schutkowski M 2009, 524:335-344.

107. Bui HH, Sidney J, Li W, Fusseder N, Sette A: Development of an epitope conservancy analysis tool to facilitate the design of epitope-based diagnostics and vaccines. BMC Bioinformatics 2007, 8:361.

108. Frahm N, Adams C, Draenert R, Feeney M, Sango K, Brown NV, SenGupta D, Simonis T, Marincola F, Wurcel A: Identification of highly immunodominant regions in HIV by comprehensive CTL screening of ethnically diverse populations. J Virol 2004, 78:2187-2200.

109. Hannon GJ, Rossi Jj: Unlocking the potential of the human genome with RNA interference. Nature 2004, 431(7006):371-378. 
110. Camarasa MJ, Velázquez S, San-Félix A, Pérez-Pérez MJ, Gago F:

Dimerization inhibitors of HIV-1 reverse transcriptase, protease and integrase: A single mode of inhibition for the three HIV enzymes? Antiviral Res 2006, 71(2-3):260-267.

111. Costa L, Zheng YH, Sabotic J, Mak J, Fackler OT, Peterlin BM: Nef binds p6* in GagPol during replication of human immunodeficiency virus type 1. J Virol 2004, 78(10):5311-5323.

112. Figueiredo A, Moore KL, Mak J, Sluis-Cremer N, de Bethune MP, Tachedjian G: Potent nonnucleoside reverse transcriptase inhibitors target HIV-1 Gag-Pol. PLoS Pathog 2006, 2(11):e119.

113. Herschhorn A, Oz-Gleenberg I, Hizi A: Quantitative analysis of the interactions between HIV-1 integrase and retroviral reverse transcriptases. Biochem J 2008, 412:163-170.

114. Loregian A, Marsden HS, Palu G: Protein-protein interactions as targets for antiviral chemotherapy. Rev Med Virol 2002, 12(4):239-262.

115. Rosenbluh J, Hayouka Z, Loya S, Levin A, Armon-Omer A, Britan E, Hizi A, Kotler M, Friedler A, Loyter A: Interaction between HIV-1 Rev and integrase proteins: a basis for the development of anti-HIV peptides. $J$ Biol Chem 2007, 282(21):15743-15753.

116. Zybarth G, Carter C: Domains upstream of the protease (PR) in human immunodeficiency virus type $1 \mathrm{Gag}$-Pol influence PR autoprocessing. The Journal of Virology 1995, 69(6):3878-3884.

doi:10.1186/1471-2180-10-212

Cite this article as: Paul and Piontkivska: Frequent associations between CTL and T-Helper epitopes in HIV-1 genomes and implications for multi-epitope vaccine designs. BMC Microbiology 2010 10:212.

\section{Submit your next manuscript to BioMed Central and take full advantage of:}

- Convenient online submission

- Thorough peer review

- No space constraints or color figure charges

- Immediate publication on acceptance

- Inclusion in PubMed, CAS, Scopus and Google Scholar

- Research which is freely available for redistribution

Submit your manuscript at www.biomedcentral.com/submit 